\title{
Duas novas espécies de Polygala (Polygalaceae) da região da Chapada dos Veadeiros, GO, Brasil
}

\author{
José Floriano Barêa Pastore ${ }^{1,3}$ e Maria do Carmo Mendes Marques²
}

Recebido em 24/09/2007. Aceito em 1/09/2008

\begin{abstract}
RESUMO - (Duas novas espécies de Polygala (Polygalaceae) da região da Chapada dos Veadeiros, GO, Brasil). Duas novas espécies de Polygala L. subgênero Polygala (Polygalaceae) endêmicas da região da Chapada dos Veadeiros, Goiás, são descritas sob o nome de Polygala suganumae e P. patens, ilustradas e sua morfologia comparada com espécies relacionadas.
\end{abstract}

Palavras-chave: Chapada dos Veadeiros, espécie nova, Goiás, Polygala subgênero Polygala, taxonomia

ABSTRACTS - (Two new species of Polygala (Polygalaceae) from Chapada dos Veadeiros, Goiás State, Brazil). Two new species of Polygala L. subgenus Polygala, endemic to the Chapada dos Veadeiros range, Goiás (Brazil), are described as Polygala suganumae and $P$. patens, illustrated, and their morphology is compared to related species

Key words: Chapada dos Veadeiros, Goiás State, new species, Polygala subgenus Polygala, taxonomy

\section{Introdução}

O gênero Polygala L. possui cerca de 725 espécies, sendo que a maior parte ocorre nas regiões tropicais, tanto em áreas de vegetação aberta, como os cerrados e os campos rupestres, quanto em florestas úmidas (Marques 1988; Paiva 1998). Segundo Paiva (1998) e Marques \& Peixoto (2007), o gênero é composto por 12 subgêneros.

No Brasil, Polygala (sensu Eriksen et al. 2000) está representado por quatro subgêneros, Hebeclada (Chodat) S.F. Blake, Ligustrina (Chodat) Paiva, Gymnospora (Chodat) Paiva e Polygala, os quais podem ser facilmente delimitados pela sua morfologia (Marques 1984; 1988; Marques \& Peixoto 2007). O subgênero Polygala é o mais diverso, sendo caracterizado principalmente pelas sépalas persistentes nos frutos e carena cristada (Paiva 1998). Ele está representado no Brasil pelas seções Cinclinia DC. e Timutua DC., sendo esta última com cerca de 150 espécies predominantemente neotropical, das quais 90 ocorrem no Brasil (Paiva 1998).

São escassos os dados na literatura sobre a quantidade de espécies endêmicas do gênero Polygala no Brasil. Durante a elaboração do capítulo sobre as espécies de Polygalaceae no Catálogo de Espécies Raras no Brasil, ainda inédito, foi constatado que no Cerrado brasileiro existem várias espécies restritas a uma área circular com diâmetro inferior a $100 \mathrm{~km}$, principalmente nas regiões da Serra do Cipó, Serra da Canastra (MG) e Chapada Diamantina (BA). Das quatro espécies do gênero Polygala endêmicas da região da Chapada dos Veadeiros (Goiás) que poderiam ser incluídas no Catálogo de Espécies Raras no Brasil, apenas P. marquesiana J.F.B. Pastore \& T.B. Cavalcanti está descrita. Duas delas estão sendo descritas neste trabalho e uma permanece inédita.

\section{Resultado e discussão}

As duas novas espécies descritas neste trabalho inserem-se no subgênero Polygala seção Timutua por apresentarem cálice persistente nos frutos, carena cristada, estilete com cavidade pré-estigmática sem formato de coifa esférica e com um apêndice superior e bainha de estames não ciliada nas margens.

Polygala suganumae J.F.B. Pastore \& Marques, sp. nov. Tipo: BRASIL. Goiás: Cavalcante, caminho para a

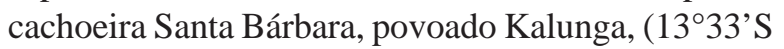
$\left.47^{\circ} 38^{\prime} \mathrm{W}\right), 7 / \mathrm{III} / 2003$, fl. fr., Pastore \& Suganuma 380 (holótipo CEN, isótipo RB, BR, NY, K).

Haec species P. hygrophila Kunth affinis sed habitu frondoso et ramosissimo vel rarius minus ramoso, racemis

\footnotetext{
1 Universidade Estadual de Feira de Santana, Departamento de Ciência Biológicas, Laboratório se Sistemática Molecular de Plantas, Rodovia 116, Km 3, 44031-460 Feira de Santana, BA, Brasil

2 Instituto de Pesquisas Jardim Botânico do Rio de Janeiro, Rua Pacheco Leão 915, 22460-030 Rio de Janeiro, RJ, Brasil

3 Autor para correspondência: jfpastore@ hotmail.com
} 
angustis conicis et floribus parvis 2,9-3,2 $\mathrm{mm}$ longis, bracteis $1-1,4 \times 0,4-0,5 \mathrm{~mm}$, sepalis externis valde maculatis et internis (alis) 2,4-2,9×1,8-2,2 mm differt. Fig. 1-16

Ervas eretas a subarbustos, bianuais, $30-60(-72) \mathrm{cm}$ alt.; caule simples partindo da raiz, distalmente ramificado a muito ramificado, 4-alado na base, pubérulo com tricomas curto-clavados ou clavados; raízes lignificadas. Folhas todas alternas, caducas apenas na porção proximal, subsésseis, papiráceas; lâminas (5-)7-23x 0,4-0,6 mm, lineares, ápice apiculado, margens não ciliadas, glabriúsculas, tricomas curtos, clavados, maculadas, com glândulas amarelo-escuras. Racemos 15-27×5-7 $\mathrm{mm}$, até $50 \mathrm{~mm}$ incluindo a raque desnuda de frutos, densifloros; brácteas 1-1,4×0,4-0,5 mm, lanceoladas, ápice atenuado, ciliadas, fortemente maculadas por glândulas alvacentas que acompanham a nervura principal, caducas em frutificação, 3-4 vezes maiores que as bractéolas; bractéolas lanceoladas; pedicelos 0,2-0,4 mm compr., glabros. Flores amareloesverdeadas, 2,9-3,2 mm compr.; sépalas externas glabras ou ciliadas apenas próximo ao ápice, fortemente maculadas por glândulas alvacentas; sépalas externas inferiores 1-1,4×0,9-1 mm, ovais, ápice obtuso; sépalas externas superiores $0,9-1,1 \times 0,5-0,6 \mathrm{~mm}$, estreitamente ovais, ápice obtuso, livres em quase toda sua extensão; sépalas internas (alas) 2,4-2,9×1,8-2,2mm, largamente elípticas a suborbiculares, não ciliadas, mais longas que os frutos maduros, maculadas por glândulas alvacentas; carena 2,1-2,3 mm compr., cristada, cristas 2-4(-5), lobos curtos, com glândulas amarelo-escuras dispostas ao longo do dorso, persistentes nos frutos maduros; pétalas laterais ca. 2,1×1,1-1,4 mm; ápice da cavidade pré-estigmática com tufo de tricomas abundantes. Cápsulas 1,9-2×1,6-1,8 mm, largamente elípticas a suborbiculares, maculadas por glândulas alvacentas; sementes 1,6-1,8×0,6-0,7 mm, cilíndrico-elipsóides ligeiramente curvadas, pubérulas, tricomas retos à levemente ondulados; apêndices com lobos livres, conados apenas na base, 1,1-1,5×0,4-0,5 mm, alcançando de metade até o comprimento total das sementes.

Parátipos: BRASIL. Goiás: Cavalcante, Comunidade Kalunga, caminho para a cachoeira Santa Bárbara, 13³3'44"S, 47³8'29'”W, 26/II/2005, fl., fr., Pastore \& Aquino 1273 (CEN); 6/VII/2003, fl., fr., Pastore \& Suganuma 413 (CEN); 6/VII/2003, fl., fr., Pastore \& Suganuma 422 (CEN); Estrada para Araí, $13^{\circ} 40^{\prime} 16.8^{\prime}$ 'S $47^{\circ} 28^{\prime} 30.2^{\prime \prime} \mathrm{W}$, alt. $1088 \mathrm{~m}, 6 / \mathrm{VII} / 2003$, fl., fr., Fonseca et al. 5034 (IBGE, RB e HRB).

Morfologia e taxonomia - Polygala suganumae está relacionada à outras espécies da série Timoutoidea Chodat principalmente por apresentar o caule 4-alado na base, racemos densifloros, corola persistentes nos frutos e sementes cilíndrico-elipsóides, com apêndices desenvolvidos. É mais afim à $P$. hygrophila Kunth, da qual se diferencia facilmente pelo hábito muito mais ramificado e frondoso, racemos estreito-cônicos, além das flores menores, entre 3-3,2 $\mathrm{mm}$ ( $v s .3,5-4,3 \mathrm{~mm}$ ), brácteas de $1-1,4 \times 0,4-0,5 \mathrm{~mm}$ ( $v s .1,9-2 \times 0,8 \mathrm{~mm})$, sépalas externas fortemente marcadas por glândulas manchas alvacentas (vs. sem pontuações ou fracamente maculadas) e sépalas internas (alas) 2,4-2,9×1,8-2,2 mm (vs. 3,2-3,5× 2,3-2,5 mm), além das cápsulas maculadas por glândulas alvacentas ( $v s$. não glandulosa ou com pequenas glândulas esparsas).

Distribuição geográfica e status de conservação Polygala suganumae tem ocorrência restrita ao município de Cavalcante (região da Chapada dos Veadeiros, Goiás). Existem registros de coletas apenas em duas localidades separadas por cerca de $21 \mathrm{~km}$. O fato de existir apenas dois pontos de coleta dificulta a avaliação da área de ocorrência, que segundo os critérios da International Union for Conservation of Nature and Natural Resources - IUCN (2007) pode ser caracterizada por um polígono convexo mínimo. Avalia-se, no entanto, que a área de ocorrência de $P$. suganumae pode ser considerada restrita a uma área menor do que $20 \mathrm{~km}^{2}$. Desta forma, é recomendado, segundo os critérios da IUCN, inseri-la na categoria de espécie vulnerável, VU D2.

Ecologia-Polygala suganumae ocorre preferencialmente em campos limpos e campos limpos rupestres. Encontrada crescendo a margens de trilhas da região, em solos arenosos. Coletada nos meses de fevereiro, março e julho, possivelmente apresenta flores e frutos nos meses de fevereiro a julho, época com maior incidência de chuvas na região.

Etimologia - O epíteto específico é uma justa homenagem à bióloga Dra. Elisa Suganuma que colaborou na coleta de diversos espécimes de Polygalaceae, incluindo as coleções-tipo das espécies aqui descritas.

Polygala patens J.F.B. Pastore \& Marques, sp. nov. BRASIL. Tipo: Goiás: Cavalcante, fazenda Renascer, Ponte de Pedras, 1353'09' S, 47³1'17'W, 980 m, 6/III/2003, fl., fr., Pastore \& Suganuma 430 (Holótipo CEN; isótipos RB, K, NY).

Haec species P. atropurpurea A. St.-Hil. \& Moq. affinis sed foliis linearibus patentibus, bracteis ciliatis caducis post fructificationem, corollis caducis in fructibus maturis differt.

Fig. 17-32

Ervas eretas a subarbustos, bianuais, $20-40 \mathrm{~cm}$ alt.; caule distalmente ramificado, proximalmente cilíndrico ou levemente alado, distalmente alado, frondoso, pubérulo, com tricomas curto-clavados; raízes 
lignificadas. Folhas alternas, brevemente caducas na base do caule, cartáceas; lâminas $(3,5) 5-12,3 \times 0,4-0,9 \mathrm{~mm}$, lineares a estreito obovais, ápice apiculado, pubérulas, tricomas curto-clavados, maculados por glândulas amarelo-escuras. Racemos 10-45×4-5 mm, até $110 \mathrm{~mm}$ incluindo a raque desnuda de frutos, densifloros; maculados por glândulas amarelo-escuras; brácteas 0,6-0,7×ca. $0,4 \mathrm{~mm}$, triangulares, ciliadas, fortemente maculadas por glândulas amarelo-escuras, caducas em frutificação, ca. 2 vezes maiores que as bractéolas; bractéolas lineares; pedicelos curtíssimos, 0,3-0,4 mm compr., glabros. Flores atropurpúreas, 2,8-2,9 mm compr.; sépalas externas não ciliadas, fortemente maculadas por glândulas amarelo-escuras; sépalas externas inferiores $1-1,2 \times c a .1 \mathrm{~mm}$, orbiculares, ápice arredondado; sépalas externas superiores $0,6-0,9 \times$

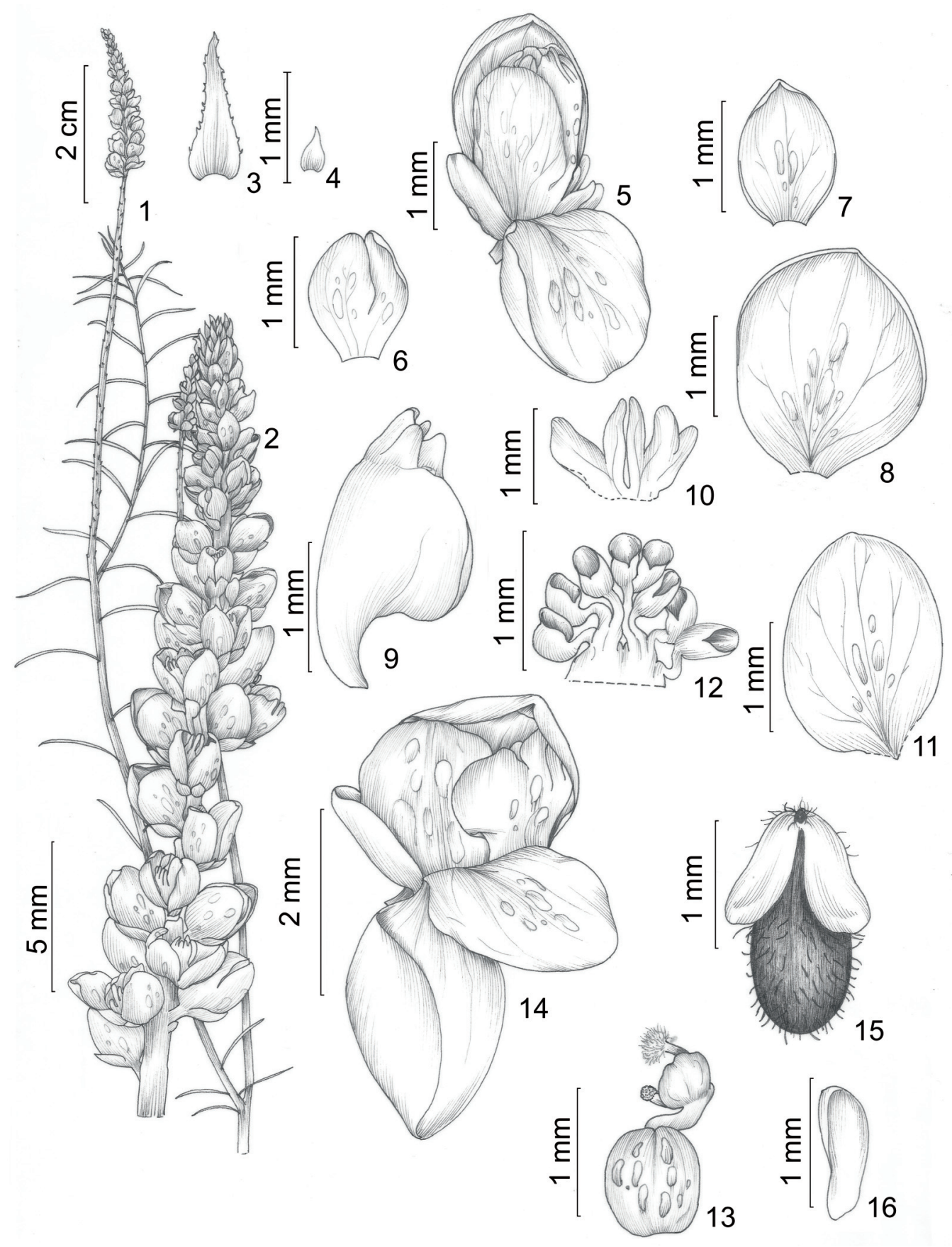

Figuras 1-16. Polygala suganumae J.F.B. Pastore \& Marques 1. Hábito. 2. Inflorescência. 3. Bractéolas. 4. Bráctea. 5. Flor. 6. Sépalas externas superiores. 7. Sépala externa inferior. 8. Sépala interna (ala). 9. Carena. 10. Ápice da carena. 11. Pétala lateral. 12. Androceu. 13. Gineceu. 14. Fruto com cálice persistente. 15. Semente. 16. Apêndice da semente (1-16 Pastore \& Suganuma 380). 
0,4-0,6 mm, ovais a suborbiculares, ápice obtuso, livres em quase toda sua extensão; sépalas internas (alas) $1,3-1,8 \times 1,1-1,4 \mathrm{~mm}$, largamente ovais ou orbiculares, ápice arredondado, não ciliadas; carena 2,1-2,2 mm compr., cristada, cristas 4-6 lobos estreitos e longos; fortemente maculadas por glândulas amarelo-escuras no dorso, caducas nos frutos maduros, pétalas laterais, 1-1,8 mm larg., mais longas que a crista da carena; ápice da cavidade pré-estigmática com tufo de tricomas abundantes. Cápsulas 1,2-1,3×1,3-1,8 mm, suborbiculares a obladas, fortemente maculadas por glândulas amarelo-escuras; sementes 1-1,3×0,6-0,9 mm, largamente ovóides a piriformes, densamente pubérulas, patentes a subpatentes; apêndices com lobos livres conados apenas na base, $0,4-0,5 \times 0,3-0,4 \mathrm{~mm}$, alcançando de $1 / 3$ a $4 / 5$ do comprimento total das sementes.

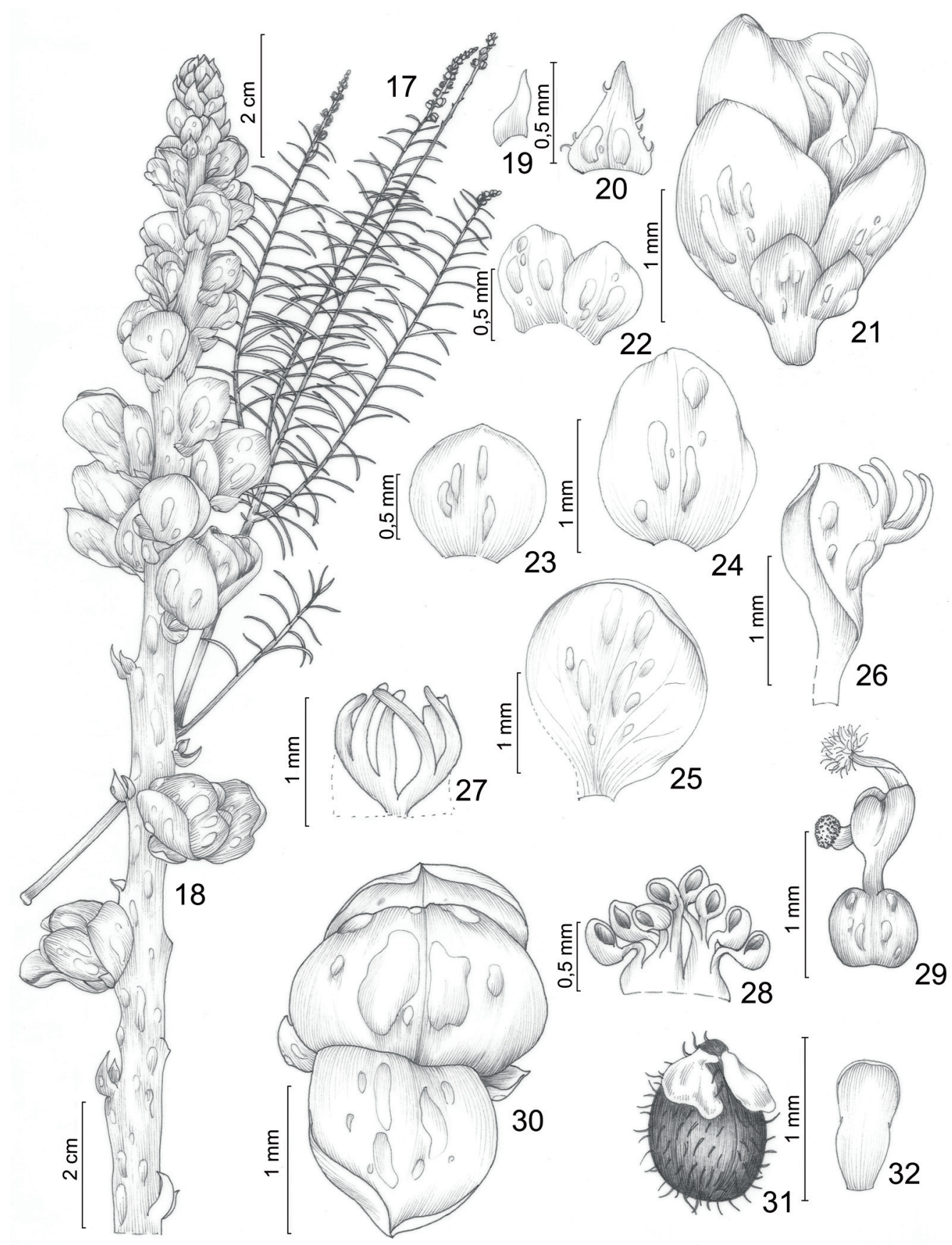

Figuras 17-32. Polygala patens J.F.B. Pastore \& Marques 17. Hábito. 18. Inflorescência. 19. Bractéolas. 20. Bráctea. 21. Flor. 22. Sépalas externas superiores. 23. Sépala externa inferior. 24. Sépala interna (ala). 25. Pétala lateral. 26. Carena. 27. Ápice da carena. 28. Androceu. 29. Gineceu. 30. Fruto com cálice persistente. 31. Semente. 32. Apêndice da semente (17-31. Pastore \& Suganuma 430). 
Parátipos: BRASIL. Goiás: Cavalcante, fazenda Renascer, Ponte de Pedras, 6/V/2002, fl., fr., Pastore 13 (CEN, RB); idem, Chapada dos Veadeiros, cerrado a margem da estrada GO-118, próximo ao rio das Almas, 21/V/1994, fl., fr., Aparecida da Silva \& Proença 1953 (IBGE).

Morfologia e taxonomia - A análise morfológica apontou uma possível relação filogenética entre $P$. patens e algumas espécies que, segundo Marques (1988), estão distribuídas em diferentes séries de Polygala subgênero Polygala seção Timutua. São elas: P. tenuis DC. e P. nudicaulis A.W. Benn. (série Tenues Chodat), $P$. subtilis Kunth e $P$. saprophytica Chodat ex Grondona (série Trichospermae Chodat) e P. atropurpurea A.St.-Hil. \& Moq. (série Timoutoideae Chodat) além de P. ceciliana Marques \& J.F.B. Pastore não incluída em nenhuma série. (Marques \& Pastore 2006). Os caracteres morfológicos avaliados presentes nas espécies citadas acima são: formato ovóide da semente, pétalas laterais relativamente amplas, presença de glândulas cróceas nas peças florais e frutos (característica não presente em P. nudicaulis A.W. Benn.) e sépalas internas mais longas que os frutos. Desta forma aguardam-se estudos que possam melhor delimitar as séries de Polygala seção Timutua, antes de inserir $P$. patens alguma série.

Dentre as espécies relacionadas acima, Polygala patens apresenta maior afinidade morfológica com P. atropurpurea A. St.-Hil. \& Moq., da qual difere pelas folhas lineares, patentes e com ca. $1 \mathrm{~cm}$ compr. (vs. escamóides, 1-2×ca. 0,5 mm), brácteas ciliadas e caducas em frutificação ( $v s$. não ciliadas e persistentes após a queda dos frutos), além da corola caduca (vs. persistente) nos frutos maduros, sementes com apêndice foliáceos que alcançam de $1 / 3$ a $4 / 5$ do comprimento total das sementes ( $v s$. ausentes ou curtíssimos alcançando até $1 / 10$ do comprimento total das sementes) e flores de 2,8-2,9 mm (vs. 2,1-2,4 mm).

Distribuição geográfica e status de conservação Polygala patens é endêmica de Cavalcante (região da Chapada dos Veadeiros, Goiás). Existem registros de coletas apenas em duas localidades separadas por ca. $17 \mathrm{~km}$. Uma das localidades onde esta espécie foi coletada se encontra dentro da fazenda Renascer que explora a área economicamente através do ecoturismo. A localidade de ocorrência é de difícil acesso e o manejo adotado para a área teve pouco impacto sobre a população de $P$. patens nos últimos anos. Ainda assim, como colocado para P. suganumae, descrita acima, também é recomendado inserir $P$. patens na categoria de espécie vulnerável, VU D2.

Ecologia - Polygala patens ocorre em cerrado rupestre com solos arenosos, sem evidências que seu florescimento esteja relacionado ao fogo. É interesse observar que Polygala atropurpurea, sua espécie mais afim, ocorre em campos limpos e seu florescimento está associado por vezes a queimadas. Polygala patens foi coletada nos meses de março e maio, possivelmente apresenta flores e frutos nos meses de fevereiro a junho, quando ocorre a maior incidência de chuvas na região.

Etimologia - $\mathrm{O}$ epíteto patens é uma referência às folhas patentes encontradas nessa espécie.

\section{Agradecimentos}

Agradecemos aos técnicos da Embrapa Recursos Genéticos \& Biotecnologia e aos curadores dos Herbários IBGE e UB, pelo empréstimo de espécimes; ao Dr. Cássio Van der Berg, pela revisão das diagnoses em latim e ao Dr. Alessandro Rapini pela revisão do texto; à Dra. Vera Regina Barêa, pela ajuda financeira as expedições que resultaram na coleta dessas espécies novas; à Ana Lúcia, pela ilustração; à Carla de Lima pelas ilustrações apresentadas.

\section{Referências bibliográficas}

Chodat, R.H. 1893. Monographia Polygalacearum. Mémoires de la Société de Physique et d'Histoire Naturelle de Genève 31: $1-500$.

Eriksen, B.; Stähl, B. \& Persson, C. 2000. Polygalaceae. In: G. Harling \& L. Andersson (eds.). Flora of Ecuador 65: 1-130.

International Union for Conservation of Nature and Natural Resources (IUCN) [Unión Internacional para la Conservación de la Naturaleza y Recursos Naturales.] 2001. IUCN Red List Categories and Criteria, Version 3.1. IUCN, Gland, Switzerland and Cambridge, United Kingdom. http://www.iucn.org.

Marques, M.C.M. 1984. Poligalas do Brasil II, Seção Gymnospora Chod. do Gênero Polygala L. (Polygalaceae). Rodriguésia 36: 31-34.

Marques, M.C.M. 1988. Polígalas do Brasil V, seção Polygala (Polygalaceae). Arquivos do Jardim Botânico do Rio de Janeiro 29: 1-114.

Marques, M.C.M. \& Pastore, J.F.B. 2006. Duas espécies novas de Polygala L. (Polygalaceae) do Estado de Goiás e Distrito Federal (Brasil). Rodriguésia 57: 99-102.

Marques, M.C.M. \& Peixoto, A.L. 2007. Estudo Taxonômico de Polygala subgênero Ligustrina (Chodat) Paiva (Polygalaceae). Rodriguésia 58: 95-146.

Paiva, J.A.R. 1998. Polygalarum Africanum et madagascariensium prodromus atque gerontogaei generis Heterosamara Kuntze, a genere Polygala segregati et a nobis denuo recepti, synopsis monographica. Fontqueria 50: 1-346.

Pastore, J.F.B. \& Cavalanti, T.B. 2008. New species of Polygala (Polygalaceae) from Brazil. Novon 17: 90-93. 